\title{
GIS-Based Analysis of the Locations of Filling Stations in La-Nkwantanang Madina Municipal Assembly Against Ghana's Planning Standards
}

\author{
John Bosco K. Damnyag Paul Aazagreyir* \\ Department of Information Technology Studies, University of Professional Studies, Accra. Ghana
}

\begin{abstract}
The degree of noncompliance of filling stations locations with regards to the planning standards is worrying. This paper uses Geographic Information System (GIS) to analyse the locations of filling stations in La-Nkwantanang Madina Municipal Assembly(LANMMA) against the planning standards set by Ghana Town and Country Planning Department. Primary and secondary data sources were used including Global Positioning System (GPS) to capture co-ordinates of some key features. All the analyses were performed in ArcMap environment of ArcGIS10.4 using spatial statistic (Nearest Neighbour Statistic), spatial analyst and proximity (Buffering) tools. The finding of the study revealed that 37 filling stations are located along major roads in the study area with a cluster pattern of distribution. About $92 \%$ of the filling stations complied to the $15 \mathrm{~m}$ standard distance from buildings while all the filling stations are in compliance to the $10 \mathrm{~m}$ standard distance between neighbour filling stations. The study recommends that the regulatory bodies should be proactive in the discharge of their duties and ensure total compliance to all the regulations.
\end{abstract}

Keywords: GIS, Filling Stations, Location, Planning Standards and LANMMA.

DOI: $10.7176 / \mathrm{DCS} / 10-1-06$

Publication date: January $31^{\text {st }} 2020$

\section{Introduction}

In Ghana, following the first significant or commercial deep-water discovery of petroleum in 2007, filling stations locations have been on the ascendancy in urban areas across the country. Some of the filling stations are sited without adherence to the Planning Standards set by the Town and Country Planning Department or Land Use and Spatial Planning Authority. Facilities location or relocation decisions play a vital role in strategy planning of wide rages of firms. In every economy, nationwide petroleum products have salient contributory role and key drivers of industrial activities (Chinambus 2011). In Nigeria petroleum accounts for as high as $78 \%$ Gross Domestic Product and up to $90 \%$ of the Nigeria's Total Revenue and foreign exchange earnings (Mohammed et al' 2014). In Europe and Asia, oil accounts for $32 \%$ of energy consumption, whilst in the Middle East oil accounts for $53 \%$ of energy consumption (Amponsah and Opei, 2014).

Geographic Information Systems (GIS) provide the appropriate tools for analyzing the effective factors on spatial data and non-spatial data (Bowman and Lewis, 2006). A study by Oloko-oba (2016) showed the use of GIS technology has proven powerful to the achievement of location analysis of filling stations in Ilorin, Kwara State, Nigeria. Location of firms or facilities ensures satisfying demands against set of constraints at minimum cost. For proper location of facilities, customers, who are assumed to be already located at points or on routes, facilities that will be located, a space in which customers and facilities are located, and a standard that indicates geographical and chronological distances between customers and facilities must be adhered to (Farahani 2009).

There is the need for proper planning prior to development in order to control the potential negative ramifications likely to emanate from haphazard erection of structures. According to (Taylor, Sichinsawbwe and Chansa 2016), it is generally important in the planning process for development particularly in the urban centres, to give much consideration to activities that reduce hazards. Moreover, according to (Rana and Garg 2014) filling stations are considered as undesired or obnoxious facilities under the obnoxious facilities location model. In this study, desired facilities are defined as facilities which are accepted by inhabitants to be placed in closer areas while undesired facilities are those which are never desired to be placed by the inhabitants and they are at times referred to as obnoxious facilities. However, some filling stations are located without regard to the planning standards set by the appropriate regulatory bodies in some countries including Nigeria and Ghana.

According to (Mohammed, Musa and Jeb 2014), GIS-based analysis of the location of filling stations in Metropolitan Kano against the physical planning standards failed to assess the distributional pattern of filling stations. Also, (Oloko-oba et al.2016) conducted a research on assessment of filling stations in Ilorin, Kwara state, Nigeria Using Geospatial Techniques and more recently (Tah 2017) researched on GIS-based locational analysis of petrol filling stations in Kaduna Metropolis. However, although the above studies were conducted in Nigeria using country specific planning standards, little attention has been paid to deploy GIS in analysing filling stations locations against the planning standards set by the towns and country planning departments or land use and spatial planning authority in Ghana. This paper presents GIS-based analysis of the location of filling stations in La- 
Nkwantanang Madina Municipal Assembly against the planning standards. The paper deploys ArcGIS 10.4 as the analysis tool specifically using Spatial Statistics (Nearest Neighbour Statistic) and Proximity (Buffer) Analysis.

The main objective of this study is to analyse the locations of filling stations in La-Nkwantanang Madina Municipal Assembly against the planning standards.

The Specific Objectives are:

- To map out all the filling stations in the study area

- To Determine the distributional pattern of the filling stations in the study area

- To Assess the compliance level of filling stations to planning standards in the study area

\section{Literature Review}

Research theories are a strings of declarations or ideologies devised to clarify a group of facts or phenomena, especially one that has been repeatedly tested or widely accepted and can be used to make predictions about natural phenomena (Akeampong 2013). The study uses obnoxious location model and planning standards of Ghana. Obnoxious location model was first developed by Church and Garfinkel in 1978. The model had been modified by several researchers. The latest modification was done by Murray and Church in 2008 using geographic information systems (GIS). The model grouped facilities into two; desired facilities and undesired facilities.

Desired facilities are those which are accepted by inhabitants to be placed closer them. Undesired facilities are those which are never desired to be placed in nearby areas by the inhabitants and they are termed under what is known as obnoxious facilities (Rana and Garg, 2014; Taylor, Sichinsawbwe, and Chansa, 2016). Undesired facilities provide disservice or negative effects on nearby ecosystem; filling stations, incinerators, poultry farms, landfills or sewage plants, airports and others (Melachrinoudis 2011). Hence their location as undesired facilities should be guided by some planning standards to ensure safety. For the purpose of this research, the following planning standards by the Town and Country Planning Department would be used. Safe distance from buildings, boundary or fixed source of ignition shall be $15 \mathrm{~m}$ from the installation of storage tanks at filling plants for both car cylinders and domestic cylinders. The plant shall not be located near hazardous areas. Flammable liquids etc. shall be stored at least $10 \mathrm{~m}$ from the fence wall. Since filling stations are obnoxious facilities the standards stipulate that filling stations should be sited at least $15 \mathrm{~m}$ distance from buildings and $10 \mathrm{~m}$ distance from other filling stations.

\section{Conceptual Framework for Location of Petrol Filling Station in Ghana}

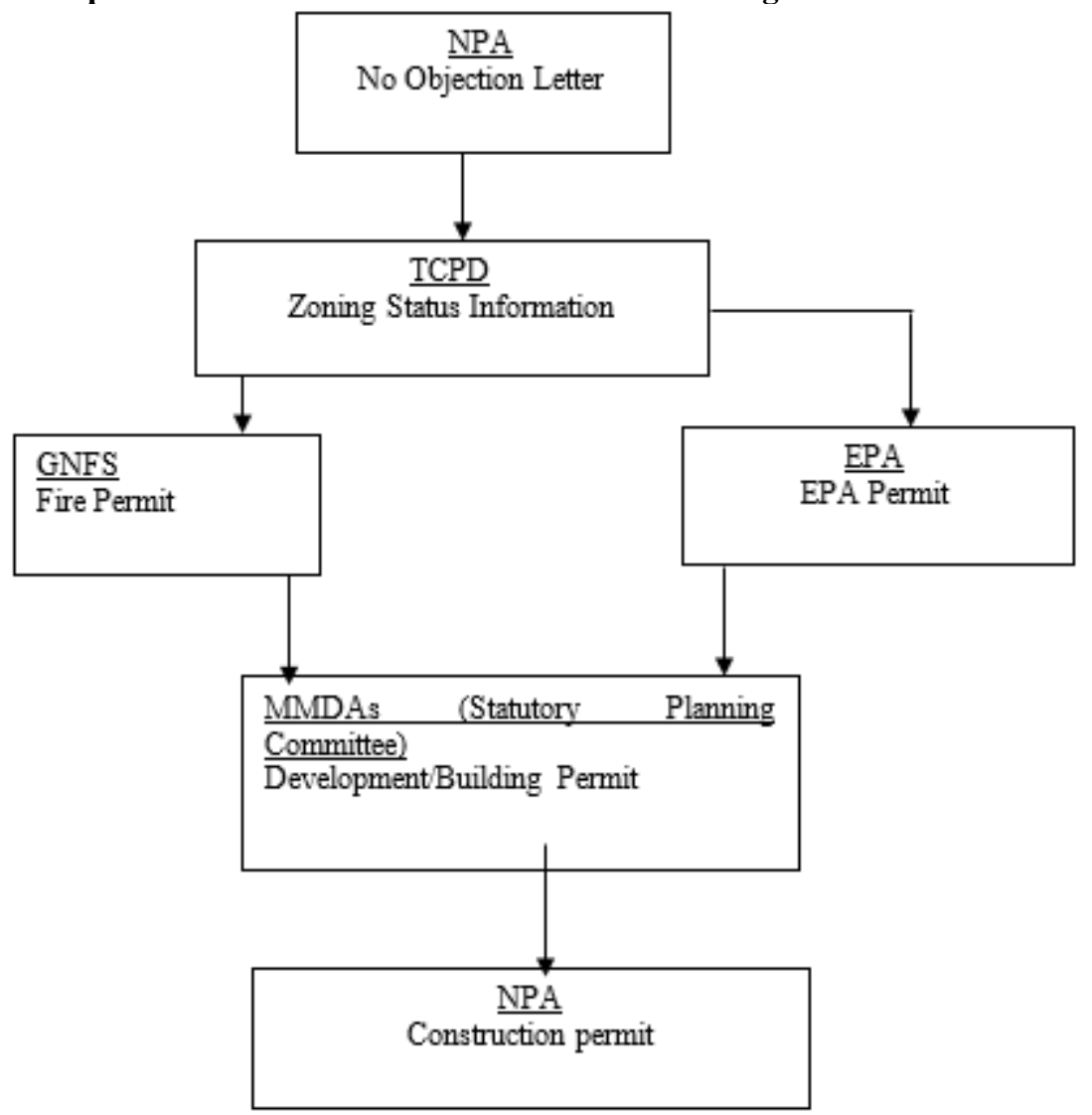

Source, NPA, 2015

An entrepreneur who is interested in setting up a petrol filling station in Ghana first applies to the National 
Petroleum Authority (NPA) with relevant supporting documents and the NPA issues a no objection letter if all their requirements are met. The no objection letter is submitted to the Town and Country Planning department with the supporting documents for adherent to planning standards and if satisfactory, the investor then proceeds to the Environmental Protection Agency (EPA) for EPA permit and to the Ghana National Fire Service (GNFS) for fire permit with the no objection letter and other documents. The district or municipal assembly is then contacted with the EPA permit, GNFS permit, letter of no objection and others documents and if all requirements are met, the investor then resubmit all these permits and documents to NPA for construction permit to start work.

(Tah 2017) in a study on "GIS-based locational analysis of petrol filling stations in Kaduna Metropolis", The findings observed the existence of two hundred and twenty-seven (227) filling stations located along twenty-six (26) roads in the study area at the time of study. Majority of the filling stations met the standard criteria of locating the nearest pump $15 \mathrm{~m}$ distances from road. Among the filling stations that did not meet these criteria, 50\% are independent markets, $33 \%$ are major marketers and $17 \%$ are Nigeria National Petroleum Corporation (NNPC). Also, $400 \mathrm{~m}$ distances compliance between filling stations to filling stations, only $24 \%$ could not meet the minimum distance from their neighbours while $76 \%$ of the filling stations met the minimum distance. Distances of filling stations to health facilities only $86 \%$ of the stations met the standards while $14 \%$ did not meet. His study did not determine the distributional pattern of the locations of filling stations in the study area. Also, the planning standards used for the analysis are different from the planning standards in Ghana. Besides, assessing the compliance status of filling stations with different standards, the assessment was limited to only health facilities and distances between neighbour filling stations.

In another study by ( Olusola 2017) resolving potential chaos associated with spatial distribution of gas filling stations in urban centres for sustainable planning" the study revealed that there are 34 petrol filling station in the study area and the location pattern can be said to turn towards clustering. Also $17(50 \%)$ of the petrol filling stations have their nearest neighbour filling stations on either side of the road locating outside the recommended radius of 300 metres. While 11(32.35) of the petrol filling stations comply with the minimum distance of 100 metres from schools and $29(85.29 \%$ ) comply with the minimum distance of 100 metres from hospitals. Olusola's study determined the distributional pattern of the filling stations locations in the study area. Yet his study did not also consider all buildings for the compliance status analysis, his study included only schools and hospitals. (Khahro and Memon 2017) researched on GIS based land suitability analysis for petrol stations. Their study shown that there are 62 existing petrol stations in the study area. About 26(42\%) petrol stations are located in the most suitable zone, $20(32 \%)$ in moderately suitable zone, $11(18 \%)$ less suitable zone $5(8 \%)$ in the less suitable zone and $5(8 \%)$ in the not suitable zone.

(Oloko-oba et al 2016) undertook a study titled, Assessment of filling stations in Ilorin, Kwara state, Nigeria using Geospatial techniques, the study observed that, there are two hundred and twenty-five (225) filling stations in the study area. The spatial pattern of distribution of filling stations in the study area is a clustered pattern with Nearest Neighbour Ratio(NRR) of 0.43 and a Z-score of -16.14 . The compliance status analysis result revealed $97.3 \%$ does not satisfy the $400 \mathrm{~m}$ apart from the nearest station while only $2.7 \%$ are in conformity to the guideline with respect to distance apart. Also $98.7 \%$ deviate from the $2 \mathrm{~km}$ radius of four stations with $1.3 \%$ in compliance. However, all the stations ensured that the drainage from their site does not flow into a river and does not lie within pipeline or high-tension cable right of way. Their study also used different planning standards for the compliance status analysis from the other studies. Their study portrayed the highest non-compliance status of $97.3 \%$ filling stations locations with regards to neighbour filling stations locations in the study area. Their study did not present any empirical result on the statement that, all the stations ensured that the drainage from their site does not flow into a river and does not lie within pipeline or high-tension cable right of way. (Taylor, Sichinsawbwe and Chansa 2016) "Public Perceptions on location of filling stations in the city of Kitwe in Zambia". The study revealed that $77.38 \%$ of filling stations in the city of Kitwe were not located according to established planning standards, guidelines and regulations.

Furthermore, (Mohammed, Musa and Jeb 2014) researched on the title GIS-Based Analysis of the location of filling stations in Metropolitan Kano against the physical planning standards. Their study revealed that, there exist two hundred and fourteen (214) filling stations located along forty- three (43) roads at the time of study. Only eight stations (4\%) did not meet the criteria of $15 \mathrm{~m}$ minimum distance from roads. On distance between filling stations, more than one-quarter of the filling stations did not satisfy the standard of 400metre distance from the nearest neighbour. On distance of filling station to health facilities, only few of the stations (2\%) could not meet the criteria. Their study did not determine the distributional pattern of the location of filling stations in the study area. The study provided all the inventory of filling stations in the study area including compliance status analysis of roads. However, their study did not also consider all buildings for the compliance status analysis, their study only included distance between filling stations and neighbour filling stations and distances between filling stations and hospitals. In a study on site selection for small gas station using GIS by (Aslani and Alesheikh 2011), the results revealed that, Analytical Hierarchy Process(AHP) and Fuzzy Analytical Hierarchy Process(FAHP) have more flexibility among the weighting methods. Also among the integrating methods, index overlay has a higher 
degree of accuracy. In their study, mathematical principle in weighting information layers was used. The research made use of knowledge driven weighting such as AHP and FAHP. Nevertheless, their study did not use any standard as a benchmark for the analysis.

\section{Research Methodology}

\subsection{Research Design}

Spatial analysis of vector data model using Geographic Information System(GIS) was used to analyse locations of filling stations in La-Nkwantanang Madina Municipal Assembly against the planning standards based on the quantitative approach. The basis for this design was apt for the study in that, the researchers try to assess the compliance status of filling stations locations in La-Nkwantanang Madina Municipal Assembly against the planning standards.

La Nkwantanang Madina Municipal Assembly(LaNMMA) was established by Legislative Instrument (L.I) 2030 and inaugurated in June 2012. The municipality covers a total land area of 74.4 square kilometres and has a total population of 111,926 as at 2010 Population and Housing Census. LaNMMA is an economically active area with a vibrant economy. The major classifications of the economics activities in the municipality includes commerce, agriculture, service and manufacturing. The diversity of the municipality's economy reflects on the vibrancy of the area.

The La Nkwantanang Madina Municipal Assembly is located at the northern part of Greater Accra Region and lies between latitude $5.6784^{\circ} \mathrm{N}$ and longitude $0.1713^{\circ} \mathrm{W}$. It is boarded on the west by the Ga East Municipal Assembly, on the east by the Adentan Municipal Assembly, the south by Accra Metropolitan Assembly, the north by the Akwapin south district assembly.

\subsection{Data Collection}

Primary and secondary data sources were used including Global Positioning System(GPS) to verify filling stations locations and also capture co-ordinates of some key features. The secondary data were obtained from National Petroleum Authority(NPA) and Environmental Protection Agency(EPA). List of filling stations on paper were obtained from the National Petroleum Authority(NPA), an agency under the Ministry of Energy responsible for regulating the petroleum downstream industry in Ghana. Shape file of the filling stations locations were received from Environment Protection Agency(EPA). The Global Positioning System(GPS) was used to capture features of buildings as the primary data.

\subsection{Data Analysis}

ArcCatalog was used to create shape files, the shape files were imported into ArcMap environment. All the analyses were performed in the ArcMap environment of ArcGIS10.4. The ArcMap generated the map of all filling stations in the study area which help achieve the first objective of the study; to map out all the filling stations in the study area. To determine the distributional pattern of the filling stations in the study area, this was achieved in ArcMap environment using spatial statistic (Nearest Neighbour Statistic). Finally, to assess the compliance level of filling stations to planning standards, proximity (Buffering) analysis in the ArcMap environment was conducted.

\section{Results of the study}

\subsection{Map of all filling stations in the study area}

Figure 1 shows the map of all filling stations in the study area. In all there are 37 filling stations in the study area. All the filling stations are sited along major roads in the area. From field observation, some filling stations have added super markets to their operations. A typical example is Sel filling station behind University of Professional Studies, Accra (UPSA) Mosque and a bunch of others. 


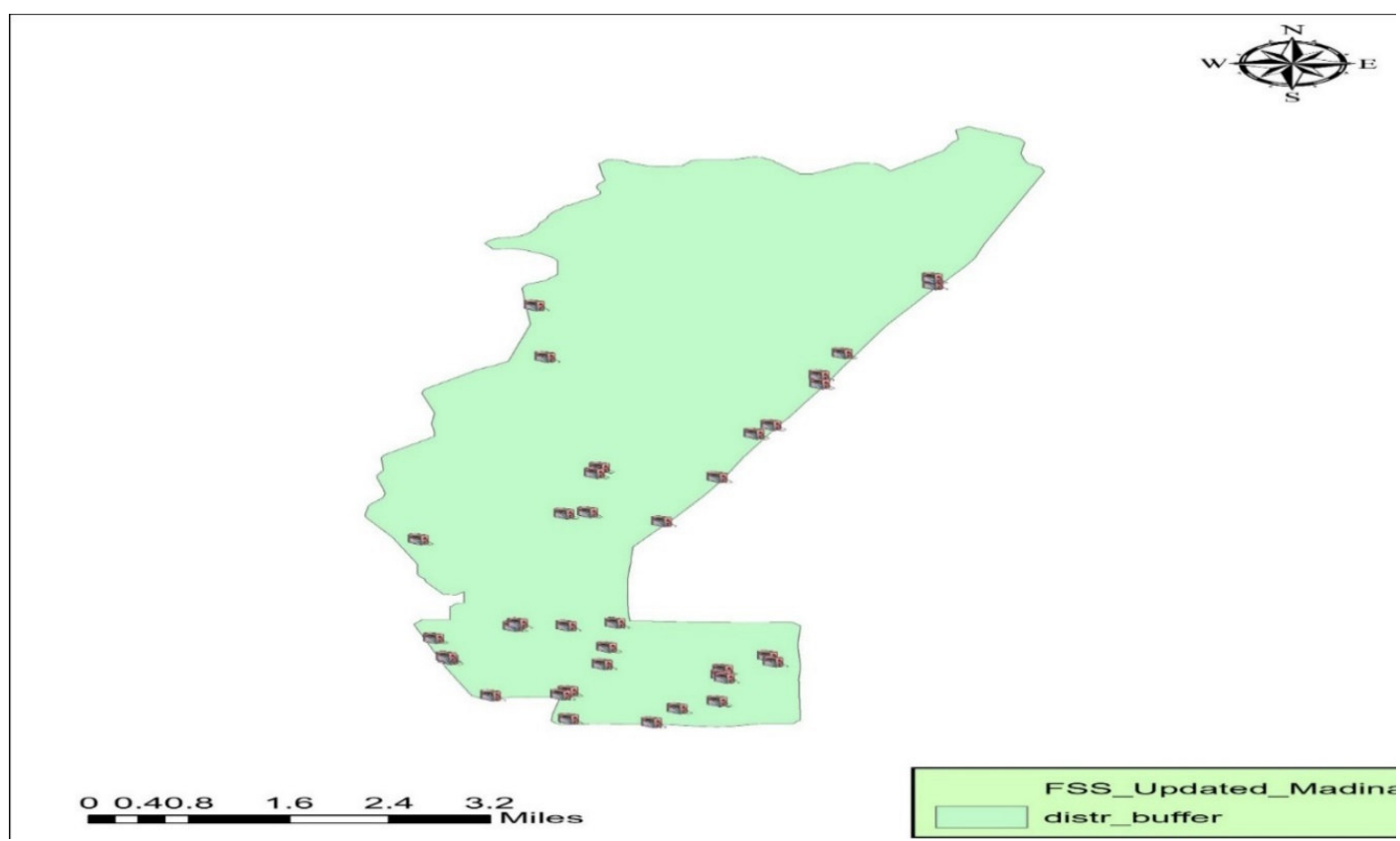

Figure 1: Map of all Filling Stations and their Locations in the Study Area

4.2 Distributional pattern of filling stations locations in La-Nkwantanang Madina Municipal Assembly Assembly (LaNMMA).

Figure 2 shows the distributional pattern of the filling stations locations in La-Nkwantanang Madina Municipal Assembly. The distributional pattern of filling stations locations in La-Nkwantanang Madina Municipal Assembly is clustered. The Nearest Neighbour Analysis Statistics in figure 2 are; Nearest Neighbour Ratio(NNR) of $0.713337, \mathrm{Z}$-score of -3.335876 and a p-value of 0.000850 which is highly significant.

\section{Average Nearest Neighbor Summary}

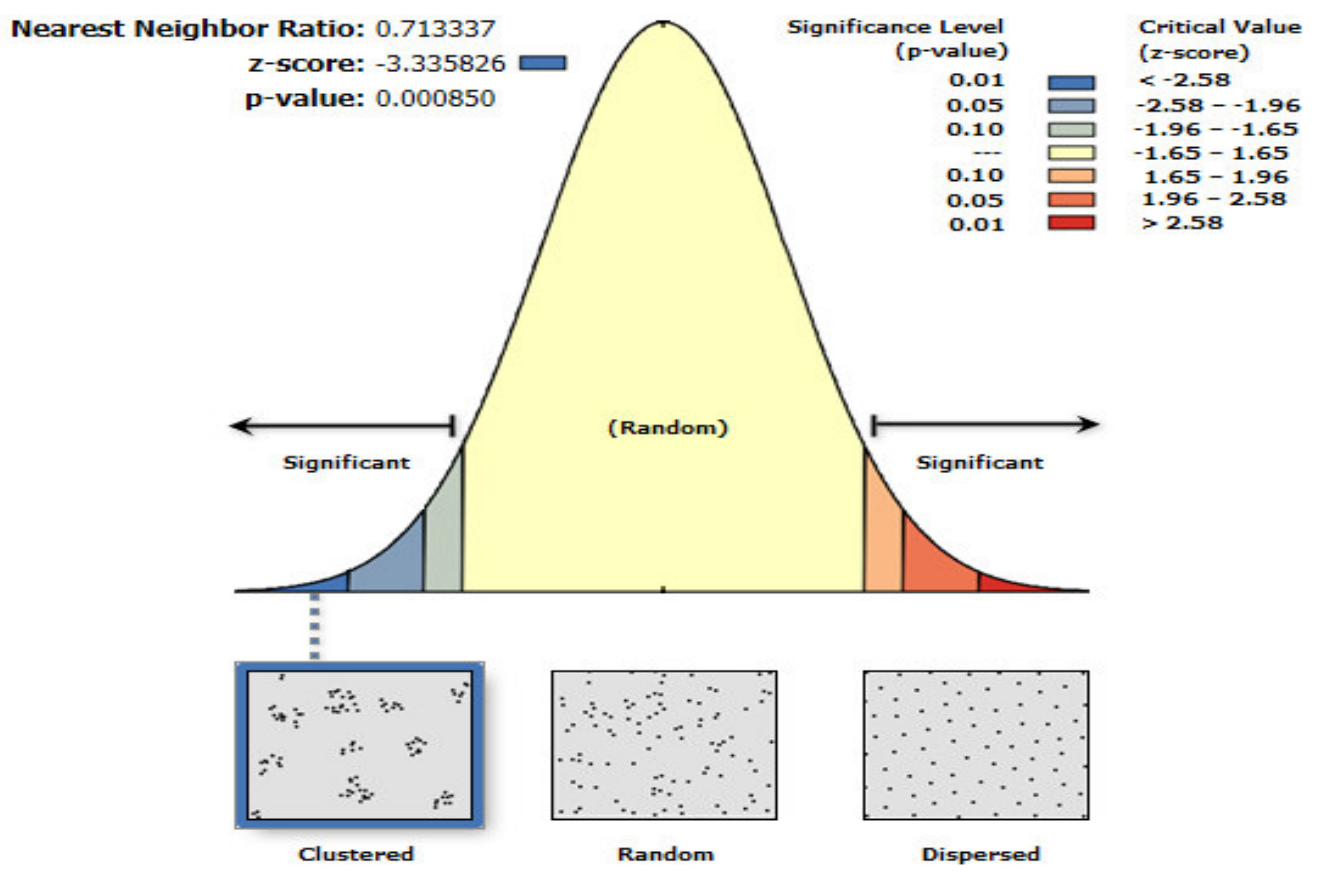

Given the $z$-score of -3.33582627524 , there is a less than $1 \%$ likelihood that this clustered pattern could be the result of random chance.

Figure 2: Nearest Neighbour Analysis Result of Filling Station in the Study Area 
4.3 Buffer analysis of $10 \mathrm{~m}$ distance between filling stations.

Figure 3 shows Buffer compliance status analysis results of filling stations locations against the $10 \mathrm{~m}$ minimum standard distance from other station. All the 37 filling stations in LaNMMA complied to the 10m standard distances between Neighbour filling stations. For visibility reason, a layer is extracted from the $10 \mathrm{~m}$ buffer analysis map in figure 3 to show clearly the $10 \mathrm{~m}$ buffer performed surrounding the filling stations.
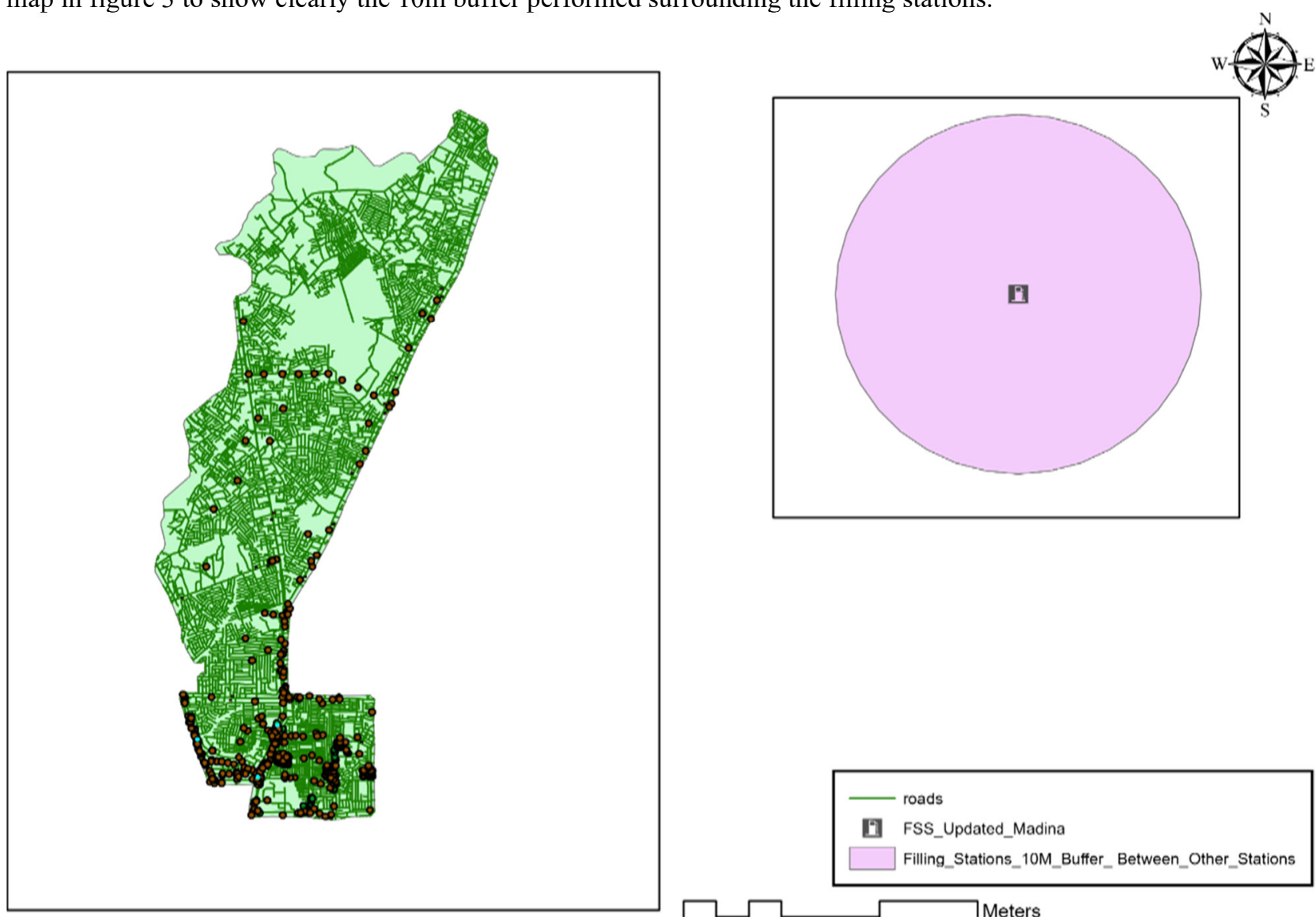

Figure 3: Map of Filling Stations Conformity with Respect to the 10m Distance to Nearest Station

4.4 Buffer analysis results of $15 \mathrm{~m}$ filling stations locations to buildings.

Figures 4 and 5 show compliance status analysis results of filling stations locations with regards to the $15 \mathrm{~m}$ minimum standard distances from buildings. For visibility reason, layers are extracted from the $15 \mathrm{~m}$ buffer analysis map in figure 4 to show clearly the $15 \mathrm{~m}$ buffer performed around the filling stations. The results show compliance and non-compliance of the filling stations locations with regard to the planning standards. About $92 \%$ of the filling stations in the study area complied to the $15 \mathrm{~m}$ standard distance to buildings while $8 \%$ did not comply to the $15 \mathrm{~m}$ standard distances as shown in figure 5 . 

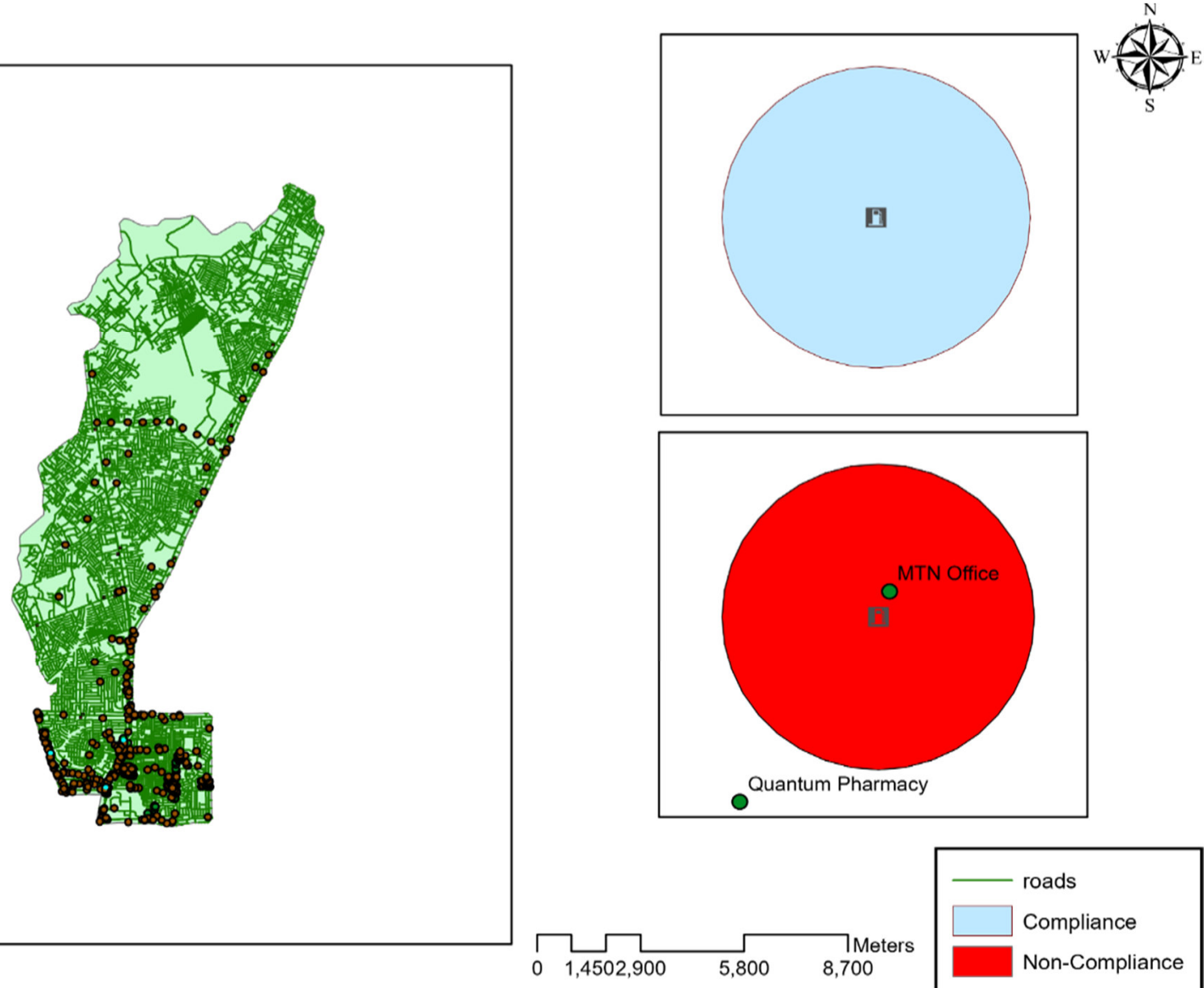

Figure 4: Map of Filling Stations Conformity with Respect to the $15 \mathrm{~m}$ Distance to Buildings.

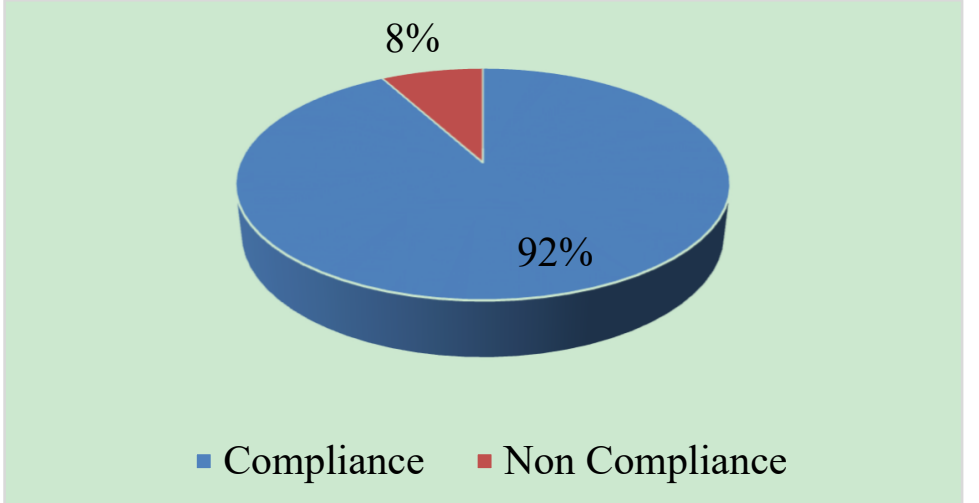

Figure 5: Pie Chart showing percentages of compliance status of filling stations to buildings with regard to the $15 \mathrm{~m}$ minimum standard distances.

\section{Discussion}

The Map of all the filling stations locations in the La-Nkwantanang Madina Municipal Assembly showed that, majority of the stations are sited close to busy areas and along busy streets. This can be said to follow Central Place Theory(CPT). Central Place Theory primarily means places that render convenient point of focus for consumers for the purchase of goods and services; CPT depends on high accessibility and quality of being at the centre of transportation systems. (Taylor, Sichinsawbwe, and Chansa, 2016). Hence the locations of filling stations in the study area as seen in figure 1 is supported by Central Place Theory.

The distributional Pattern of filling stations locations in the study area is clustered as shows in figure 2 . The clustering means, the inter distances between a filling stations and other filling stations is somehow nearer but not very close. The distributional pattern is the way it is probable because of the strategic location choice by the entrepreneur who primary aim is to maximise profit. In literature, it was discovered that, there are two key factors in locating filling stations; Location choice made by the owner of the filling station and Locational criteria specified 
by the regulating bodies. The p-value of 0.000850 which is highly significant means that, there is $99.915 \%$ (i.e 1 p-value * 100) assurance level that the distributional pattern of the filling stations is clustered.

The buffer compliance analysis results of filling stations locations to other stations gave a $100 \%$ compliance of the filling stations to the $10 \mathrm{~m}$ minimum standard distances. This means all the 37 filling stations in the study area are in compliance to the minimum standards as showed in figure 3 . This finding is in sharp contrast to a study conducted by (Taylor, Sichinsawbwe, and Chansa, 2016) on the topic 'Assessment of filling stations in Ilorin, kwara state, Nigeria using Geospatial techniques'. In their study, about $97.3 \%$ of the filling stations did not satisfy the $400 \mathrm{~m}$ apart from the nearest station.

The $15 \mathrm{~m}$ buffer analysis results showed that 34 out of the 37 filling stations representing $92 \%$ of the filling stations in the study area complied to the $15 \mathrm{~m}$ standard distance to buildings while $8 \%$ representing 3 filling stations did not comply to the $15 \mathrm{~m}$ standard distances as shown in figures 4 and 5 . It was found in literature that, Non-complying filling stations pose a risk to the environment and are a source of concern in case of fire explosion (Muzenda 2015) . Going by this statement, noncompliance of filling stations irrespective of the number involved is a source of worry. Perhaps the noncompliance is as a result of two key factors; human influence by the opulent and also the fact that development is dynamic.

\section{Policy Implications}

About $8 \%$ of the filling stations in the study area are not complying to the planning standards. Due to the high risky nature of the petroleum sector, even the least non-compliance level should pose a worry to all stakeholders. The regulatory bodies need to be more proactive and effective in discharging their duties. This may require the development of real-time Geo-Information System for remotely monitoring operations of filling stations since development is dynamic. The Town and Country Planning Department should incorporate all parameters such street hawkers, filling station having super markets, Kebab sellers, mobile money vendors and other mini structures into the planning standards.

\section{Conclusions}

The study concludes that, there are 37 filling stations located along major roads in the study area. The distributional pattern of the filling stations locations is clustered. There is $100 \%$ compliance of filling stations to neighbour filling stations with regards to the $10 \mathrm{~m}$ minimum standard distances. About $92 \%$ of the filling stations in the study area complied to the $15 \mathrm{~m}$ standard distance to buildings while $8 \%$ did not comply to the $15 \mathrm{~m}$ standard distances.

\section{References}

Olusola, O. O., 2017. Resolving Potential Chaos Associated with Spatial Distribution of Gas Filling Stations in Urban Centres for Sustainable Planning. Journal of Advanced Research Design , 39(1), pp. 9-18.

Adsavakulchai, S. \& Huntula, C., 2010. Optimum site selection of natural gas vehicles station in Bangkok using geographic information system. ournal of Petroleum and Gas Engineering, 1(5), pp. 89-94.

Akeampong, E. A., 2013. The Impact of Library Usage on the Productivity of Faculty of the University of Ghana, Accra: University of Ghana.

Amponsah, R. \& Opei, F. K., 2014. Ghana's downstream petroleum sector: An assessment of key supply chain challenges and prospects for growth. International Journal of Petroleum and Oil Exploration Research, 1(1), pp. 001-007.

Anon., n.d.

Aslani, M. \& Alesheikh, A. A., 2011. Site selection for small gas stations using GIS. Scientific Research and Essays, 6(15), pp. 3161-3171.

Bowman, D. \& Lewis, D., 2006. Sears holding corporation GIS navigation and mapping system.ArchNews online, s.l.: s.n.

Chinambus, C., 2011. A Study on market structure and competition. The petroleum Industry in Zambia.

Khahro, S. A. \& Memon, Z. A., 2017. GIS Based Land Suitability Analysis for Petrol Stations. International Journal of Civil Engineering and Technology, 8(10), pp. 01-06.

Melachrinoudis, E., 2011. The location of undesirable facilities. In Foundations of location analysis, pp. 207-239.

Mohammed, M. U., Musa, I. J. \& Jeb, D. N., 2014. GIS-based analysis of the location of filling stations in metropolitan Kano against the Physical Planning Standards. American Journal of Engineering Research, 3(9), 147-158., pp. 147-158.

Muzenda, A., 2015. Petrol Filling Stations. The Time Bomb of African Cities .

Oloko-oba , O. M. et al., 2016. Assessment of Filling Station in Ilorin, Kwara State, Nigeria Using Geospatial Techniques. International Journal of Scientific Research in Computer Science, Engineering and Information Technology, 1(2).

Rana, J. \& Garg, D., 2014. Algorithm for Obnoxious Facility Location Problem. International Journal of Advancements in Technology, 5(4), pp. 96-104. 
Rana, R. \& Garg, D., 2014. Algorithm for Obnoxious Facility Location Problem International Journal of Advancements in Technology. International Journal of Advancements in Technology.

Tah, D. S., 2017. GIS-based locational analysis of petrol filling stations in Kaduna Metropolis. Science World Journal, 12(2).

Taylor, T. K., Sichinsawbwe, C. \& Chansa, B., 2016. Public Perceptions on Location of Filling Stations in the City of Kitwe in Zambia. Developing Country Studies . 